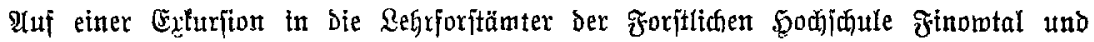

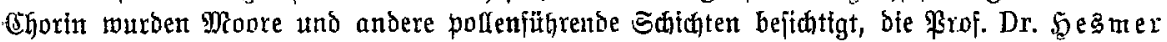

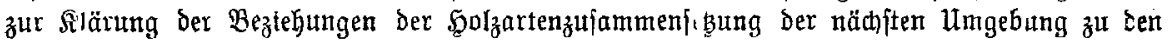

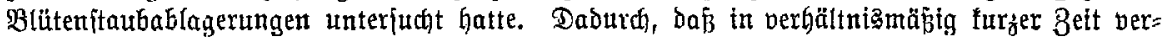
¡đifedenite Stanborte mit ifren ftart menfelnden Walbbilbern und beren wiberiptegelung in den \$ollen=, Samen= und Squppendiagrammen burd den ganzen Rauj ber Waldgejuidfte

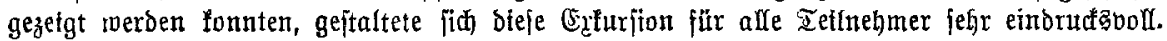

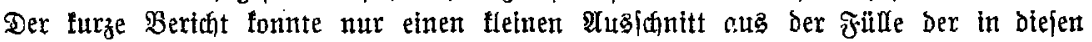
3 Tagen geletfteten Arbett bringen, bie jebem dex Teilnehmer viele Anregungen gab. ડo

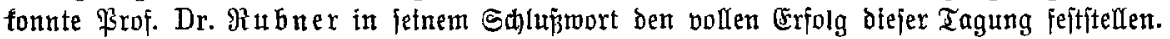

$$
\text { Эürgen Meluer. }
$$

\title{
Erfolgreicher Dogeliłhulz.
}

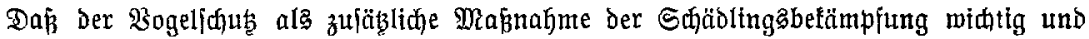

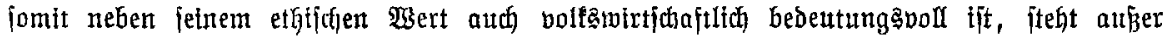

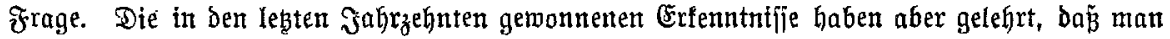

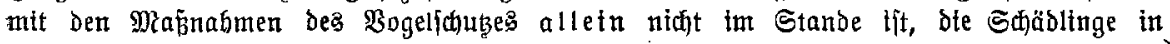

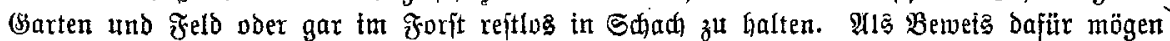

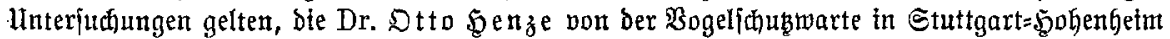

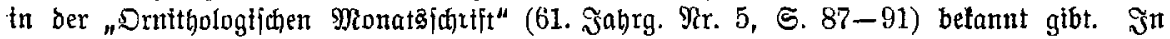

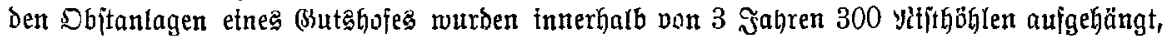

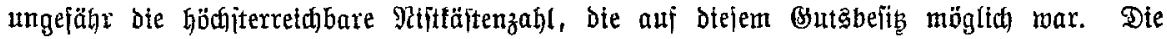

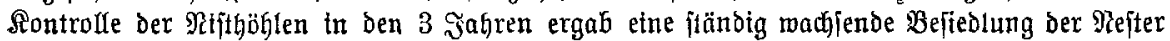

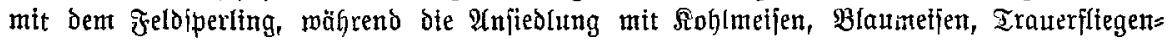

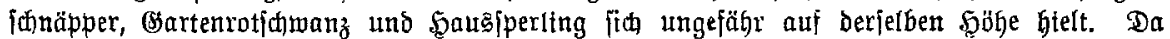

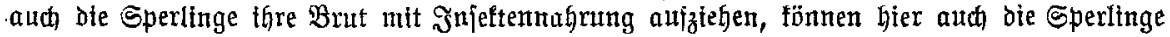

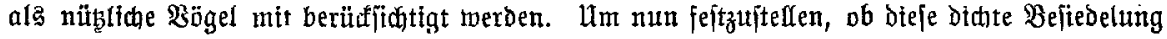
mit injeftenireffenden Bogelarten eine Berminderung ber J̃nfeftenplage in Bisfolge habe, hat

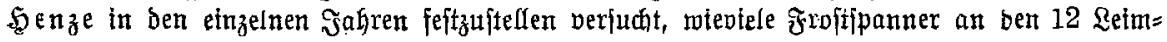
ringen, die jeden Serbjt tmmer mteder an ben Bäumen angelegt wurben, fin fingen. (5r

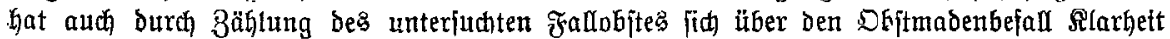

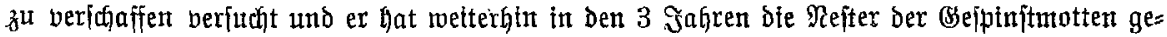

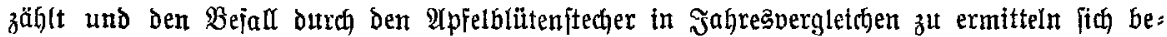

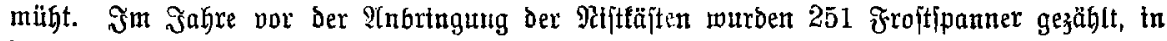

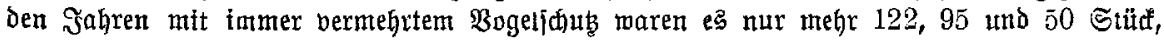

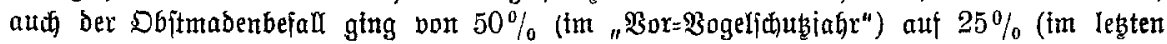
ber 3 "Bogelfdubjahre" zurüd. Dle $8 \mathfrak{a b l}$ der Befpinjtmottennejter fant in den 4 Jahren pon 153 auf 34, Der Apielblïtenitecherbefall wax, bevor Bogelfhub getrieben wurde "Der heerend" und fant bant bis zum 3. Bogeljaubjafr" auj "mittel“. Wud bieje Beobathtungen

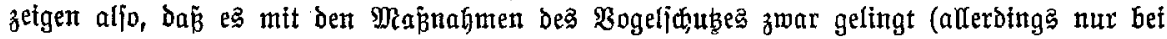

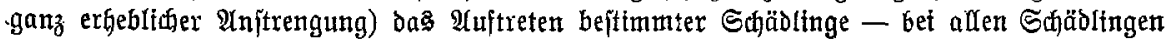

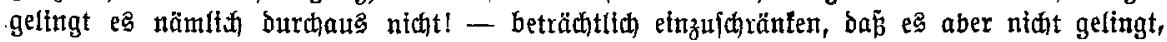

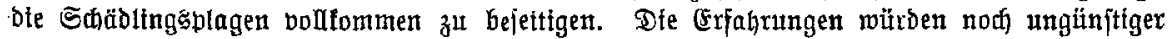

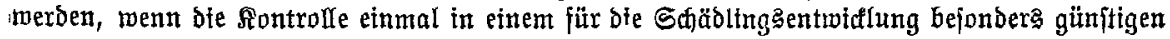

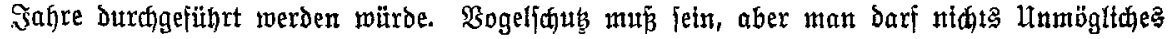
won thm verlangen.

Dr. $\mathfrak{f} x$ 